\title{
Análise de uma estaca cravada por 25 anos
}

\author{
LUIZ HENRIQUE FELIPE OLAVO - ENGENHEIRO CIVIL* \\ EnSOLO Engenharia de Solos e Fundações Ltda - Centro Universitário UniCuritiba, Centro Universitário IDD \\ ORCID: https://orcid.org/0000-0002-9894-8267
}

\begin{abstract}
RESUMO
ApRESENTA-SE UM ESTUdO dE CASO DE OBRA DE UMA CORTINA DE ESTACAS PRÉ-MOLDADAS DE SEÇÃO RETANGULAR $18 \times 40$ CM, QUE FORAM CRAVADAS EM COMPRIMENTOS ALTERNADOS DE 3 E 5 METROS PARA CONTENÇÃO DE UM SUBSOLO EM UM TERRENO, QUE FOI PARALISADA E ABANDONADA, EM AGOSTO DE 1995, SENDO QUE AS ESTACAS PERMANECERAM AINDA SEM ARRASAMENTO NO TERRENO. NO ANO DE 2020, ESTE TERRENO FOI COMPRADO, SENDO PREVISTO UM NOVO EMPREENDIMENTO NO MESMO LOCAL. ESTE NOVO EDIFÍCIO PREVIA PILARES CARREGADOS APOIADOS SOBRE ESTA CORTINA E, PARA ESTA MUDANÇA, CONSTATOU-SE QUE AS ESTACAS ESTARIAM CURTAS. OPTOU-SE POR EXTRAIR AS ESTACAS DE 3 METROS, POSSIBILITANDO A EXECUÇÃO DE ESTACAS MAIS LONGAS ENTRE AS DE 5 METROS. NO CASO DA OBRA, O PH MEDIDO NO LOCAL, COM USO DE PAPEL DE PH, FOI DE 6. POR CONTER BAstANTE

MATÉRIA ORGÂNICA E POSSUIR COR ESCURA, ERA ESPERADA A PRESENÇA DE ÁCIDOS ORIGINÁRIOS DA DECOMPOSIÇÃO DA MATÉRIA ORGÂNICA E QUE SE ENCONTRAM DILUÍDOS NO LENÇOL FREÁTICO LOCAL OU NA UMIDADE DO SOLO. PortANTO, APÓS 25 ANOS, APROVEITOU-SE PARA VERIFICAR A ESPESSURA NEUTRALIZADA DO COBRIMENTO DE CONCRETO DAS ESTACAS EXTRAÍDAS. NO TRECHO DE ESTACA EXPOSTO AO AR FOI ENCONTRADA UMA ESPESSURA DE $4 \mathrm{MM}$, NO TRECHO DE ESTACA IMERSA EM SOLO ORGÂNICO, DE 3 MM, MAS NO TRECHO EM SOLO RESIDUAL DA FORMAÇÃO GUABIROTUBA, DE APENAS 1 MM. Os SOLOS DA FORMAÇÃO GUABIROTUBA POSSUEM A CARACTERÍSTICA DE UM AQUITARDO, OU SEJA, UM SOLO ONDE, MESMO QUE EXISTA ÁGUA, NÃO POSSUI PERMEABILIDADE SUFICIENTE PARA QUE ESTA ÁGUA SE MOVA POR ENTRE SEUS GRÃOS, PROTEGENDO ASSIM O CONCRETO DA ESTACA.
\end{abstract}

Palavras-chave: durabilidade de concreto armado, neutralização, carbonatação, estacas pré-moldadas.

\section{INTRODUÇÃO}

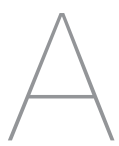

presenta-se um estudo de caso de carbonatação de estaca de uma obra de contenção com estacas pré-moldadas para uma escavação de 2,10 metros em relação ao ponto mais baixo do meio fio que foi paralisada e abandonada após a cravação das estacas.

As estacas, com seção retangular, de $18 \times 40 \mathrm{~cm}$, foram cravadas alternadamente em comprimentos de 3 e 5 metros a cada $45 \mathrm{~cm}$, paralelamente à divisa, de modo a obter uma cortina de pequena espessura. A cravação destas estacas ocorreu em agosto de 1995.

Após a cravação de parte das estacas, a obra foi paralisada e abandonada.
No ano de 2020 o terreno foi comprado sendo projetado um novo empreendimento no local. O novo edifício possuía uma escavação semelhante à do empreendimento anterior, com o piso acabado do subsolo 2,04 metros abaixo do ponto mais baixo do meio-fio, porém possuía vãos maiores, menos pilares e pilares com cargas entre 800 e $3000 \mathrm{kN}$ que seriam apoiados sobre a cortina.

Analisando-se a capacidade de carga das estacas existentes, percebeu-se que o comprimento seria insuficiente, o que levou a se deslocar uma perfuratriz para a obra, executar furos adjacentes à cortina e a extrair as estacas de 3 metros, tornando possível a execução de estacas mais fundas e com maior ca- pacidade de suporte nos vãos entre as estacas de 5 metros.

Em função de se terem extraído as estacas de 3 metros em fevereiro de 2021, escolheu-se uma estaca aleatória dentre as estacas extraídas e optou-se por medir a espessura de concreto que havia carbonatado com o uso de solução de fenolftaleína.

\section{CARACTERIZAÇÃO GEOLÓGICO- GEOTÉCNICA DA OBRA}

A obra localiza-se na Avenida Paraná, no bairro do Cabral, em Curitiba, Paraná. Está situada em uma região de meia encosta, próxima a um fundo de vale, sendo possível observar na porção superior do solo, um solo

*luiz@ensolo.com.br 
de terraço aluvionar. Subjacente a este solo encontra-se um solo argiloso de coloração ocre a avermelhada, indicando um processo incipiente de laterização. Este solo é um solo residual da formação Guabirotuba, sendo que os sedimentos da formação Guabirotuba em si aparecem logo abaixo com um contato gradual (concordante), o que indica que o solo laterítico não foi transportado.

O solo do terraço aluvionar é caracterizado por ter baixa resistência à penetração, sendo poroso, de baixa permeabilidade e elevada plasticidade (FIORI e SALAMUNI, 2012). Por conter bastante matéria orgânica, possui cor escura, sendo esperada a presença de ácidos, responsáveis por um possível $\mathrm{pH}$ abaixo de 7. No caso da obra, possui espessura de até 2 metros. $\mathrm{O} \mathrm{pH}$ medido no local, com uso de papel de pH, foi de 6 .

Subjacente ao solo do terraço aluvionar, aparece solo da formação Guabirotuba, onde percebe-se que a sua porção superior sofreu um processo de alteração, sendo classificado como um solo residual da formação Guabirotuba. Os solos da formação Guabirotuba possuem a característica de ter baixa permeabilidade, o que faz deles um aquitardo, ou seja, um solo onde mesmo que exista água, não possui permeabilidade suficiente para que esta água se mova por entre seus grãos (FELIPE, 1999, SALAMUNI et. al. 2012).

A baixa permeabilidade do solo da formação Guabirotuba faz com que seja possível a presença de um lençol de água flutuante localizado entre o solo orgânico do terraço aluvionar e o solo residual da formação Guabirotuba. O processo de alteração ao qual esteve submetido este solo, chamado de laterização, faz com que surjam óxidos, os quais são respon-

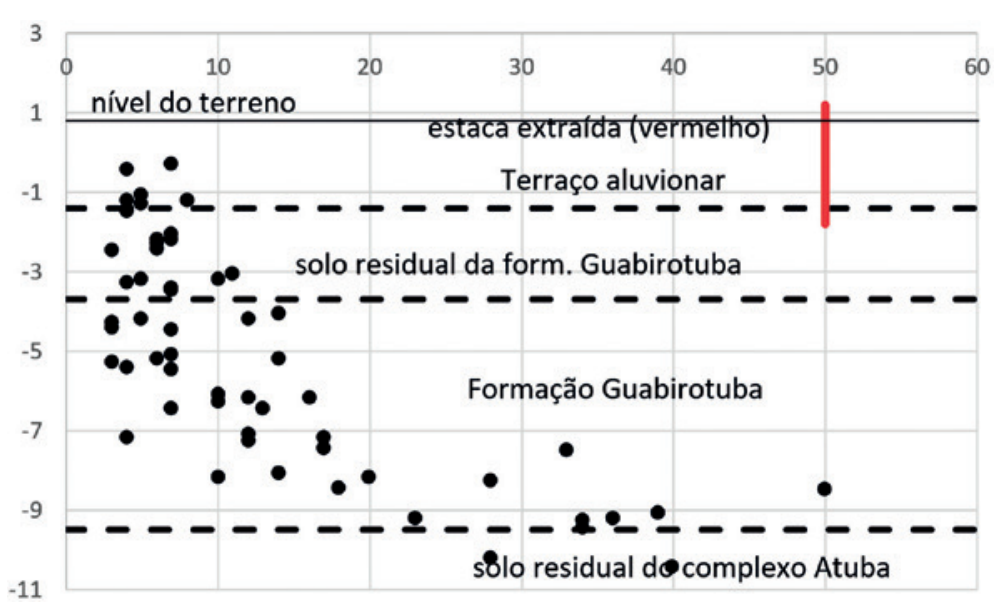

Figura 1

Índices de $\mathrm{N}_{\mathrm{SPT}}$ versus profundidade em relação ao ponto mais baixo do meio-fio, indicando as camadas de solo e a posição da estaca (em vermelho)

Fonte: o próprio autor

sáveis pela característica cor ocre e avermelhada observada. Além disso, causa a movimentação de finos do solo em direção vertical descendente, deixando o solo mais poroso e com menor resistência à penetração, o que pode ser observado nos resultados das sondagens executadas na obra, nas quais se observam resultados mais baixos de índices $\mathrm{N}_{\text {SPT }}$ do que os do solo não alterado subjacente. Medido o pH deste solo, com papel de $\mathrm{pH}$, o mesmo foi neutro $(\mathrm{pH} 7,0)$.

O solo da formação Guabirotuba é constituído por uma argila rija sobreadensada, de cor cinza. Possui baixa permeabilidade, alta resistência à penetração e baixa porosidade. Seu principal argilo mineral é a montmorilonita cálcica, que faz este solo ser expansivo. É o principal preenchimento da bacia sedimentar de Curitiba, tendo origem sedimentar. Subjacente a este solo encontram-se as rochas do complexo Atuba (embasamento cristalino da bacia), podendo ou não haver solo residual do Complexo Atuba (FIORI e SALAMUNI, 2012). Este solo aparece abaixo da cota de ponta das estacas extraídas.

A Figura 1 mostra o resultado dos ensaios de SPT realizados com a indicação das camadas de solo e a posi- ção da estaca extraída em relação a estas camadas.

\section{DURABILIDADE DE ESTRUTURAS DE CONCRETO ARMADO}

Segundo a norma ISO 6241 (ISO, 1984), durabilidade é o resultado da interação entre a estrutura de concreto, o ambiente e as condições de uso, de operação e manutenção, não sendo, portanto, uma característica inerente apenas ao material, mas também ao seu uso. No caso de estruturas de fundação e contenção a manutenção não é possível de ser executada, devendo a estrutura ser projetada para ter uma durabilidade adequada sem a necessidade de intervenções (ABNT, 2013).

A durabilidade das estruturas de concreto armado está relacionada com a não ocorrência de corrosão nas armaduras ou alterações deletérias na pasta de cimento. A corrosão das armaduras de aço é evitada, uma vez que a proteção oferecida pelo concreto é baseada no pH elevado do hidróxido de cálcio, num processo chamado de passivação.

O ambiente em que o concreto está imerso, por sua vez, possui materiais 
ácidos que reagem com o hidróxido de cálcio, formando sais de pH neutro, que tornam possível a ocorrência de corrosão nas armaduras das peças estruturais. Estes elementos ácidos podem ser o gás carbônico do ar, que reage com o hidróxido de cálcio dando origem ao carbonato de cálcio (carbonatação), ou, no caso de solos, ácidos orgânicos originários da decomposição da matéria orgânica e que se encontram diluídos no lençol freático local ou na umidade do solo.

O ataque desses elementos ácidos ocorre através dos poros do concreto, sendo que a espessura afetada depende das dimensões, quantidade e interconectividade destes poros. $\mathrm{O}$ ataque também depende do meio onde os elementos ácidos estão inseridos. Por exemplo, o gás carbônico está em meio gasoso, enquanto os ácidos do solo estão em

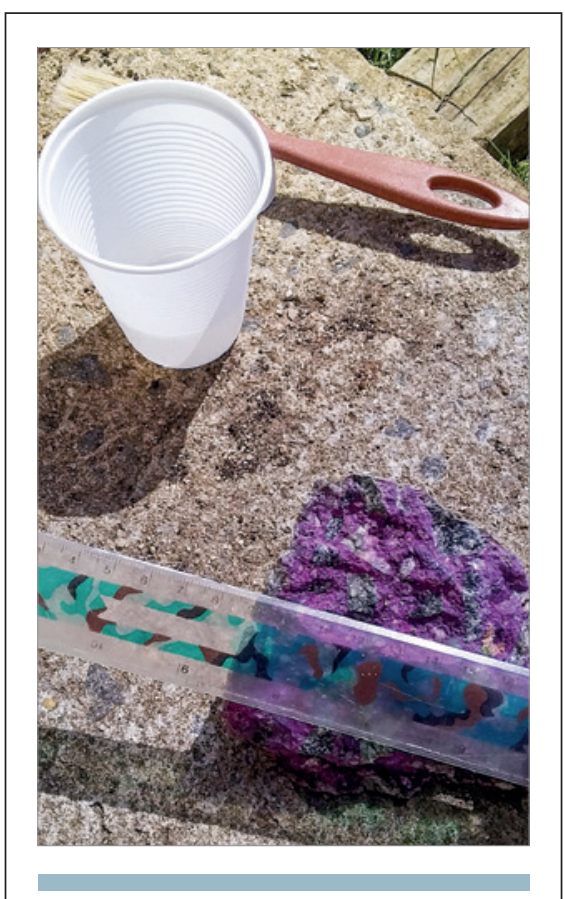

Figura 2

Espessura de carbonatação do trecho exposto ao ar, sendo medida a espessura de $4 \mathrm{~mm}$, não reagente à solução de fenolftaleína meio aquoso. Não necessariamente a permeabilidade é a mesma para estas duas situações, tornando a análise mais complexa, o que justifica a observação de dados de campo.

Desta forma, existem duas frentes para proteção de uma estrutura e garantia de durabilidade. A primeira diz respeito à resistência do concreto em si. Quanto mais resistente à compressão simples, menos poroso o concreto se torna, evitando a incursão de agentes ácidos. A outra frente diz respeito ao cobrimento, que é uma espessura que toma tempo para ser neutralizada pelos agentes ácidos. Recentemente, viu-se na revisão da norma de fundações, o aumento das exigências de resistência para os concretos utilizados em estacas, visando a maior durabilidade das mesmas (ABNT, 2019).

O envelhecimento das estruturas de concreto também pode ocorrer devido a mecanismos que deterioram componentes da própria pasta de cimento, podendo ser a lixiviação, que ocorre em presença de águas puras ou atmosferas ácidas, reações expansivas, como as que ocorrem na presença de sulfatos ou magnésio ou ainda em reações álcali-agregado, ou reações deletérias superficiais como a formação de eflorescências (MEDEIROS ET. AL., 2011).

\section{DADOS OBTIDOS EM CAMPO}

Dentre as estacas extraídas, escoIheu-se uma aleatoriamente para verificação das espessuras de cobrimento do concreto onde o $\mathrm{pH}$ já estava neutralizado. A estaca possuía a porção superior, de cerca de $40 \mathrm{~cm}$ exposta ao ar e não arrasada ainda, depois cerca 2 metros imersa em solo ácido de terraço aluvionar, com pH 6, e cerca de $60 \mathrm{~cm}$ imersa em solo residual da formação Guabirotuba, com pH neutro. Foram en- tão retiradas lascas do concreto dessas 3 regiões, as quais foram pintadas com solução de fenolftaleína a 1\% de concentração em álcool etílico 96\%. Quando se tornam de cor rosa o $\mathrm{pH}$ é superior a 8,3. Quando se tornam incolores, o pH é abaixo deste valor.

No trecho de estaca exposto ao ar, foi possível observar uma imagem da espessura neutralizada de $4 \mathrm{~mm}$ da peça na Figura 2. Ressalta-se que esta neutralização se deu em exposição à atmosfera urbana, portanto sendo considerada uma carbonatação, devido ao terreno estar localizado em uma rua que é importante eixo de transporte metropolitano, com canaleta de BRT.

Considerando-se que a espessura de carbonatação pode ser correlacionada com a raiz do tempo, através da equação 1, obtém-se um coeficiente de carbonatação, k, para este concreto igual a $0,08 \mathrm{~cm}^{2} / \mathrm{ano}$.

$x=k \sqrt{t}$

Onde $\mathrm{x}=$ espessura de carbonatação (cm), $\mathrm{k}=$ coeficiente de carbonatação (cm²/ano) e $\mathrm{t}=$ tempo (anos).

O trecho da estaca imerso em solo do terraço aluvionar apresentou espessura de cobrimento neutralizado de $3 \mathrm{~mm}$. O pH medido do solo do terraço aluvionar foi de 6, medido com papel de $\mathrm{pH}$. A acidez deste solo deve-se à presença de matéria orgânica. Uma foto da peça retirada a partir do trecho imerso em solo de terraço aluvionar pode ser vista na Figura 3.

O trecho da estaca imerso em solo residual da formação Guabirotuba, por sua vez, apresentou espessura de cobrimento neutralizado de apenas $1 \mathrm{~mm}$. Este solo possui $\mathrm{pH}$ neutro quando medido com papel de $\mathrm{pH}$, além de ser um solo pouco poroso. Ressalta-se que o 


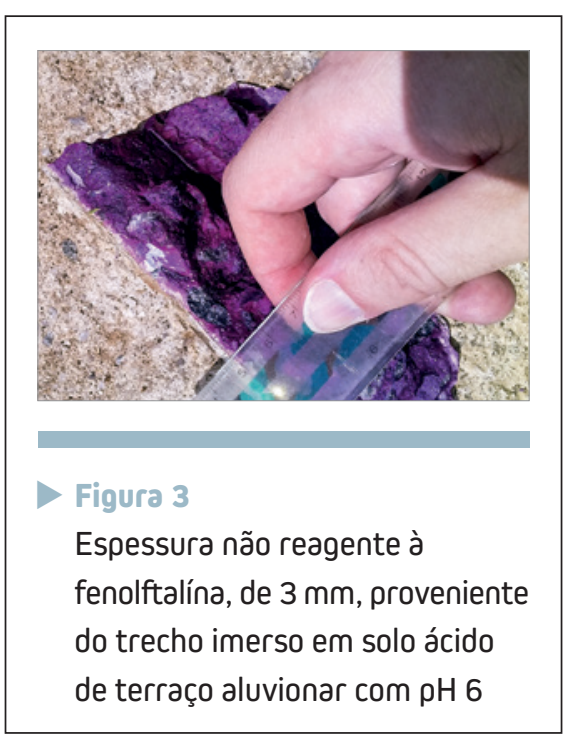

nível de água, encontra-se situado entre o terraço aluvionar e o solo residual da formação Guabirotuba, sendo o terraço aluvionar mais poroso e, portanto, com mais fluxo de água subterrânea, ainda que não se observou um volume elevado de água em nenhuma parte da obra. Uma foto da peça retirada da estaca no trecho imerso em solo residual a formação Guabirotuba pode ser vista na Figura 4.

\section{DISCUSSÃO DOS RESULTADOS}

Com base nas informações obtidas em campo, pode-se constatar que as características do solo influenciam na neutralização do cobrimento de concreto dos trechos enterrados. Foi possível observar maior espessura de cobrimento neutralizada no trecho em contato com o solo ácido do terraço aluvionar, de $\mathrm{pH}$ 6 , do que no contato com o solo neutro residual da formação Guabirotuba, de pH 7. Não apenas o pH dos solos é diferente, mas também a sua porosidade e permeabilidade, o que sugere menor fluxo de água entre os grãos de solo residual da formação Guabirotuba do que entre os grãos de solo do terraço aluvionar.

Pode-se perceber menor espessura de cobrimento neutralizada nos trechos enterrados do que no trecho exposto ao ar. Uma possível explicação para esta observação diz respeito à baixa velocidade de difusão do $\mathrm{CO}_{2}$ na água em relação ao ar, cerca de $10^{4}$ vezes menor (FIGUEIREDO E MEIRA, 2013). Soma-se a isto o fato do solo poder estar saturado mesmo acima do nível do lençol freático devido a efeitos capilares (GITIRANA JR. ET. AL., 2015). Além disso, os ácidos presentes no solo também costumam ser diferentes do ácido carbônico presente na atmosfera, sendo comuns os ácidos orgânicos de baixa massa molecular (e.g. ácido fórmico e acético) (PINHEIRO, 2012)

A estaca possui cobrimento de $30 \mathrm{~mm}$, o que faz com que, para o coeficiente de carbonatação de 0,08cm²/ano, o tempo necessário para despassivação da armadura por este mecanismo seja de aproximadamente 1400 anos.

Observa-se também uma mudança na norma de fundações (ABNT, 2019), a qual foi revisada e passou a exigir resistências e características de traço diferentes para o concreto de acordo com a classe de agressividade ambiental à qual a estaca esteja sujeita. Tal mudança foi mais sentida no caso de estacas moldadas in loco, onde passou-se a se exigir também teores de exsudação diferentes para o concreto fresco, pensando também nas condições de aplicação do mesmo. Para estacas pré-moldadas, a mudança da norma foi quanto à resistência característica à compressão do concreto, que passou de 30 para 40MPa.

\section{CONCLUSÕES}

O coeficiente máximo de carbonatação encontrado para esta estaca de concreto foi de $0,08 \mathrm{~cm}^{2} /$ ano.

Foi avaliada a espessura de cobri- mento de concreto neutralizada em diversos trechos de uma estaca pré-moldada de contenção que ficou cravada por 25 anos: um trecho exposto ao ar, um trecho imerso em solo de terraço aluvionar e um trecho em solo residual da formação Guabirotuba. Observou-se uma espessura de carbonatação de $4 \mathrm{~mm}$ para o trecho exposto ao ar, uma espessura neutralizada de $3 \mathrm{~mm}$ no trecho imerso em solo ácido com pH 6 de terraço aluvionar, e, no trecho imerso em solo residual da formação Guabirotuba, de $\mathrm{pH}$ neutro e que consiste em um solo pouco permeável e pouco poroso, uma espessura neutralizada de cobrimento de concreto de apenas $1 \mathrm{~mm}$.

O nível de água do solo no local da obra encontra-se entre o terraço

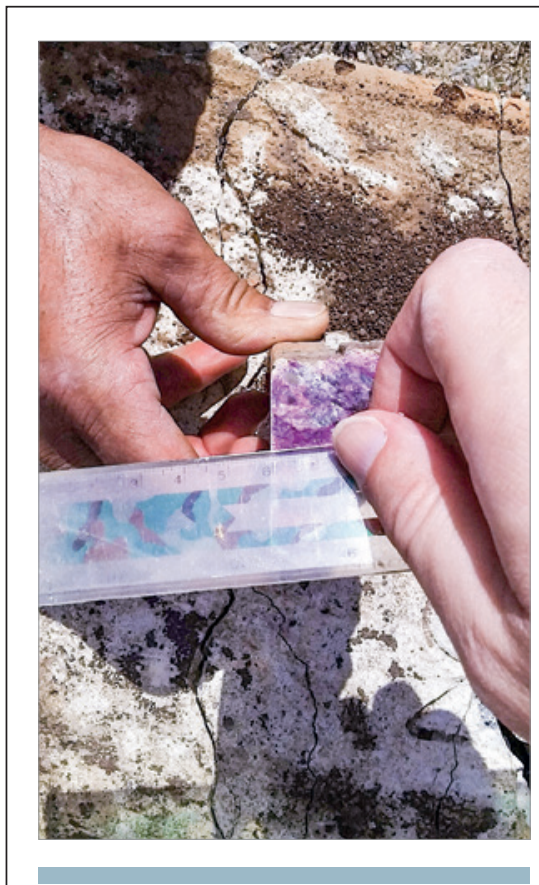

Figura 4

Espessura não reagente à solução de fenolftaleína, de $1 \mathrm{~mm}$, em lasca de concreto proveniente do trecho imerso em solo residual da formação Guabirotuba com $\mathrm{\rho H}$ neutro 
aluvionar e o solo residual da formação Guabirotuba, formando um lençol suspenso sobre o solo da formação Guabirotuba, localizado abaixo da cota da ponta da estaca extraída. Os solos da formação Guabirotuba possuem a característica de um aquitardo, ou seja, um solo onde mesmo que exista água, não possui permeabilidade suficiente para que esta água se mova por entre seus grãos, protegendo assim o concreto da estaca.

\section{DREGRÊNCIAS BIBLIOGRÁFICAS}

[1] ASSOCIAÇÃO BRASILEIRA DE NORMAS TÉCNICAS. NBR 15575 Desempenho de Edifícios Habitacionais. Rio de Janeiro, 2013.

[2] ASSOCIAÇÃO BRASILEIRA DE NORMAS TÉCNICAS. NBR 6122 Projeto e Execução de Fundações. Rio de Janeiro, 2019. 108pp.

[3] FELIPE, R.S., Erodibilidade da Formação Guabirotuba. In: Mesa Redonda Características Geotécnicas da Formação Guabirotuba. Curitiba. 1999. Anais. ABMS/UFPR. Pp. 53-63

[4] FIGUEIREDO, E.P., MEIRA, G.Boletim Técnico 6 - Corrosão de Armadura de Estruturas de Concreto. CONPAT 2013 - XIV Congreso de Control de Calidad en la Construcción. Mérida, México, disponivel para download em http://alconpat.org.br/wp-content/uploads/2012/09/B6-Corrosão-das-armaduras-das-estruturasde-concreto.pdf.

[5] FIORI, A.P., SALAMUNI, E. Geologia de Curitiba e Arredores. In: NEGRO, A. et. al. (ed.). Seminário Twincities: Solos das Regiões Metropolitanas de São Paulo e Curitiba. São Paulo. D'Livros, 2012. 512pp. ISBN 978-85-86438-40-0

[6] GITIRANA JR, G., MARINHO, F.A.M., SOTO, M.A.A. A Curva de Retenção de Água de Materiais Porosos. In: CARVALHO, J.C. et. al. (orgs.). Solos não Saturados no Contexto Geotécnico. São Paulo. Associação Brasileira de Mecânica dos Solos e Engenharia Geotécnica. 2015. 759pp. ISBN 978-85-67950-03-7

[7] INTERNATIONAL ORGANIZATION FOR STANDARDIZATION. ISO 6241 Performance Standards in building - Principles for their preparation and factors to be considered (Normalização e Desempenho dos Edifícios. Princípios de sua preparação e fatores a serem considerados). 1984

[8] MEDEIROS, M.H.F., ANDRADE, J.J.O., HELENE, P. Durabilidade e Vida Útil de Estruturas de Concreto. In: Concreto: Ciência e Tecnologia. ISAIA, G.C. (ed.). Ibracon, 2011.

[9] PINHEIRO, G.L. Ácidos orgânicos e carbono solúvel em solos e resíduos. Tese de doutorado. UFLA, Lavras, MG.

[10] SALAMUNI, E. HINDI, E.C., ROSA FILHO, E.F. Hidrogeologia de Curitiba e Arredores. In: NEGRO, A. et. al. (ed.). Seminário Twincities: Solos das Regiões Metropolitanas de São Paulo e Curitiba. São Paulo. D'Livros, 2012. 512pp. ISBN 978-85-86438-40-0

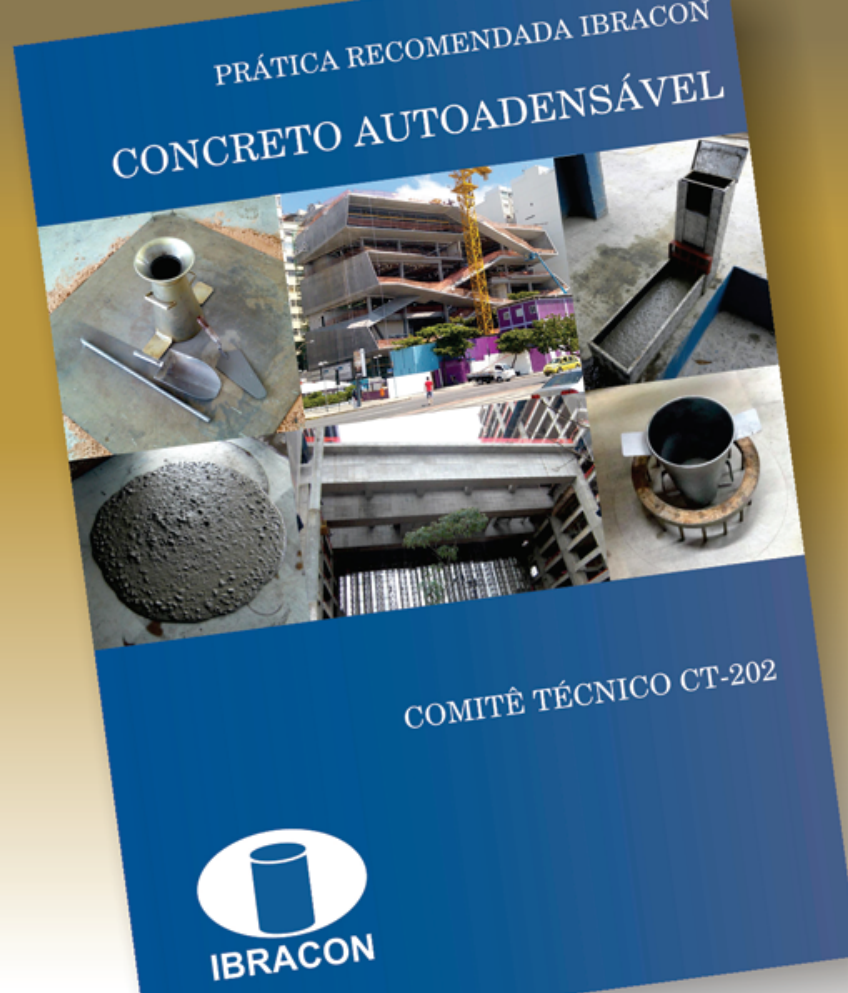

\section{Prática Recomendada IBRACON Concreio Antoadensálye}

\section{COORDENADOR Bernardo Fonseca Tutikian SECRETÁRIO Roberto Christ}

Traz para a comunidade técnica os conceitos relacionados ao concreto autoadensável, as recomendações para seleção de materiais, os métodos de dosagem, os procedimentos de mistura, as recomendações para a aceitação do concreto no estado fresco e para seu transporte, lançamento e rastreamento

A obra é resultado do trabalho do Comitê Técnico IBRACON sobre Concreto Autoadensável (CT 202), voltando-se aos profissionais que lidam com a tecnologia do concreto autoadensável nos canteiros de obras, nas indústrias de pré-fabricados, nos laboratórios de controle tecnológico e nas universidades.

\section{DADOS TÉCNICOS}

ISBN / ISSN: 978-85-98576-25-1

Edição: $1^{\mathrm{a}}$ edição

Formato: Eletrônico

Páginas: 78

Acabamento: Digital

Ano da publicação: 2015

\section{Patrocínio}

